\title{
Personal Belief in a Just World and Self - Compassion as Predictors of Body Appreciation in Individuals with Amputation Using and not Using Prosthesis
}

\author{
Farhat-ul-Ain, ${ }^{1}$ Iram Fatima ${ }^{2}$
}

\begin{abstract}
Objectives: To investigate the relationship of personal belief in just world self - compassion with body appreciation in individuals with amputation who use prosthesis and in those who do not use prosthesis.

Methods: A sample of 78 individuals using prosthesis and not using prosthesis ( $\mathrm{n}=39$ each) was selected. Cross - sectional research design was used. Urdu translated version of Personal Belief in Just World Scale (PBJW), Self - Compassion Scale and Body Appreciation Scale were used. Moderated regression analysis was used to assess if personal belief in just world and self - compassion predict body appreciation similarly or differently in the two groups using SPSS 20.
\end{abstract}

Results: Among individuals with amputation using prosthesis were $30(76.9 \%)$ men and 9(23.1\%) women while among 39 individuals not using prosthesis were $30(76.9 \%)$ men and $9(23.1 \%)$ women. Age of indivi-

Date of Submission 8-1-2016

Date of Acceptance for Publication 26-3-2016

Conflict of Interest: None

Funding Source: None

Farhat-ul-Ain ${ }^{1}$

Ms Health Psychology

Institute of Applied Psychology, University of the Punjab

Fatima I. ${ }^{2}$

Assistant Professor

Institute of Applied Psychology, University of the Punjab duals with amputation using and not using prosthesis was, $M=37.10, S D=14.30$ and $M=39.13, S D=$ 14.14 respectively. Duration of amputation of those using and not using prosthesis in years was $M=6.10$, $S D=7.74$ and $M=8.35, S D=11.82$ respectively. Duration of use of prosthesis in years was $M=3.29$, $\mathrm{SD}=3.86$. Personal belief in just world positively predicted body appreciation in both groups. Self - compassion predicted body appreciation only in individuals with amputation using prosthesis. Individuals using prosthesis had better body appreciation than those not using prosthesis.

Conclusion: Use of prosthesis helps in body appreciation of individuals with amputation. Over and above the use of prosthesis, personal belief in a just world is a personal resource that plays its role in maintaining body appreciation. However, Self - compassion aids in body appreciation among individuals with amputation using prosthesis.

Key Words: Amputation, Personal belief in a just world, Self - Compassion, Body Appreciation.

\section{Introduction}

All body parts of a person determine physical functionality and individual's interaction within the social circle. After limb amputation, an individual faces various physical, psychological and psychosocial challenges such as changes in daily functioning, occupational hindrances due to the loss of the limb, and body appreciation related concerns. ${ }^{1,2}$

Body appreciation has a crucial importance in a person's self worth. ${ }^{3}$ It becomes even more important when a person has lost an important visible body part. 
Body appreciation is the love, respect and appreciation for one's ownbody. ${ }^{4}$ Persons with higher level of body appreciation appreciate the uniqueness and healthy functionality of their body. They receive only that information from environment that protects their body image and filter out the harmful information. It reflects the ability to accept one's body as it is despite not fulfilling the ideal criteria of body as promoted by media. ${ }^{4}$

After amputation the individuals need to re-organize themselves and cope with the situation and improve their positive body image. Individual's reaction towards this unfair situation in different ways. This reaction may depend on one's belief in a just world, a self - sustained belief that one would get what he/she deserves. Personal belief, in a just world helps to believe in a fair treatment, interpret life events in a meaningful way and treat other's fairly. ${ }^{5}$ Personal belief in just world has been observed as a personal resource that is adaptive in both victims ${ }^{6,7}$ and non-victims ${ }^{8,9}$ by initiating different coping strategies and overall improve well - being.

Another important variable that is adaptive in traumatic situation is self - compassion. Self - compassion helps the individuals to accept self during a crisis time without being critical to self. ${ }^{10}$ Self - compassion is characterized as being caring and understanding of oneself in the face of failure, pain or disappointment, perceiving one's encounters as a component of the bigger human experience instead of seeing them as isolating; and holding excruciating musings and emotions in mindful awareness rather than over - identifying with them. Self - compassion has been observed to help individuals after traumatic life experiences to get adjusted in their lives. ${ }^{11}$ Self - compassion has also been found useful in enhancing satisfaction with body image and reduce body dissatisfaction. ${ }^{12,13}$ Individuals who have an amputation also suffer from body image crisis. Even the use of prosthesis itself can be very traumatic as it is a constant reminder that they have a disability. ${ }^{1}$

\section{Objectives}

1. To investigate the relationship of (1) personal belief in just world and (2) self - compassion with body appreciation in individuals with amputation who use prosthesis and those who do not use prosthesis.

Table 1: Demographic and Clinical Characteristics of Participants ( $\mathrm{N}=39$ each).

\begin{tabular}{|l|c|c|c|c|}
\hline \multicolumn{1}{|c|}{ Variables } & $\begin{array}{c}\text { Individuals with } \\
\text { Amputation Not Using } \\
\text { Prosthesis (n=39) }\end{array}$ & $\begin{array}{c}\text { Individuals with } \\
\text { Amputation Using } \\
\text { Prosthesis (n=39) }\end{array}$ & $\begin{array}{c}\text { Statistical } \\
\text { Tests }\end{array}$ & $p$ \\
\hline Gender & $f(\%)$ & $f(\%)$ & & \\
\hline Men & $30(76.9)$ & $30(76.9)$ & & \\
\hline Women & $9(23.1)$ & $9(23.1)$ & $\chi^{2}=.70$ & 1.00 \\
\hline Age $M(S D)$ & $39.13(14.14)$ & $37.10(14.30)$ & $\mathrm{t}(76)=-.13$ & .89 \\
\hline Personal Income $M(S D)$ & $14358.9(22446.34)$ & $16487.18(27856.6)$ & $\mathrm{t}(76)=.37$ & .71 \\
\hline Education $M(S D)$ & $10.69(5.19)$ & $10.77(5.31)$ & $\mathrm{t}(76)=.06$ & .94 \\
\hline Amputated Limb & & & & \\
\hline Upper Limb & $6(15.4)$ & $1(2.6)$ & & .10 \\
\hline Lower Limb & $33(84.6)$ & $38(97.4)$ & $\chi^{2}=3.92$ & .61 \\
\hline Uni-Lateral amputation & $38(97.4)$ & $36(92.3)$ & & .53 \\
\hline Bi-Lateral Amputation & $1(2.6)$ & $3(7.7)$ & $\chi^{2}=1.05$ & .61 \\
\hline Duration of amputation (in Years) $M(S D)$ & $8.35(11.82)$ & $6.10(7.74)$ & $\mathrm{t}(76)=.62$ & \\
\hline Duration of use of prosthesis (in Years) & & $3.29(3.86)$ & & \\
\hline
\end{tabular}




\section{Method and Materials}

Data was collected from 78 individuals with amputation including those who used prosthesis $(n=39)$ and who did not use prosthesis $(\mathrm{n}=39)$. Reason of amputation was accidental and occupational injury. Participants who had major limb amputation for at least 3 months were included. The sample was taken from the rehabilitation institute after taking permission from the concerned authorities. Ethical approval for the study was granted by Departmental Doctoral Programme Committee.

A self - constructed demographic information sheet was used to obtain the demographic information of the participants (gender, age, personal income and education). A medical information sheet was developed obtain specific condition related medical information of the participants that includes information related to amputated limb (lower limb/upper limb), Unilateral or bilateral amputation, age at amputation, duration of amputation, and duration of the use of prosthesis. The demographic characteristics of the participants are mentioned in the Table 1. It can be observed from the table that the two groups did not differ in demographic and clinical characteristics except for use of prosthesis.

Urdu version ${ }^{14}$ of Personal Belief in a Just World Questionnaire $^{15}$ was used to assess the personal belief in a just world. The scale consisted of 7 statements. Each statement has to be rated on 6 point Likert Scale. Cronbach alpha of the scale for current study was .95

Urdu version ${ }^{16}$ of Short - form of Self - Compassion Scale $^{17}$ was used to measure self - compassion. It comprised of 12 items and on 5 points Likert Scale. The score range was $7-60$. Sum of all items was taken to obtain overall score of self - compassion. Cronbach alpha of the scale for the current study was .62

Urdu Translated version of body appreciation scale $^{18}$ was used to measure body appreciation. It comprised of 10 items with 5 point Likert scale. Cronbach alpha of the scale for the current study was .95 .

Table 2: Descriptive of main variables in individuals with amputation using prosthesis and those not using prosthesis.

\begin{tabular}{|l|c|c|}
\hline & $\begin{array}{c}\text { Individuals with Amputation } \\
\text { Not Using Prosthesis }\end{array}$ & $\begin{array}{c}\text { Individuals with Amputation } \\
\text { Using Prosthesis }\end{array}$ \\
\hline \multicolumn{1}{|c|}{ Variable } & $M(S D)$ & $M(S D)$ \\
\hline Personal Belief in Just World & $18.08(9.63)$ & $23.69(11.74)$ \\
\hline Self - compassion & $34.64(6.93)$ & $37.51(7.57)$ \\
\hline Body Appreciation & $24.54(9.59)$ & $35.08(11.86)$ \\
\hline
\end{tabular}

Table 3: Inter - Correlations among Demographic Variables, Personal Belief in Just World, Self - Compassion, and Body Appreciation in individuals with Amputation using prosthesis (lower diagonal) and not using prosthesis (upper diagonal, $\mathrm{n}=39$ each).

\begin{tabular}{|l|c|c|c|c|c|c|c|c|}
\hline & 1 & 2 & 3 & 4 & 5 & 6 & 7 & 8 \\
\hline 1. Gender & - & .03 & .19 & .02 & -.11 & -.00 & -.17 & -.16 \\
\hline 2. Age & .04 & - & .11 & -.16 & $.50 * *$ & -.09 & .22 & -.02 \\
\hline 3. Education & .12 & .08 & - & $.43^{* *}$ & .29 & .02 & .19 & -.05 \\
\hline 4. Personal income & $-.32 *$ & -.06 & .05 & - & .03 & -.04 & .02 & -.16 \\
\hline 5. Duration of amputation & -.18 & .24 & .09 & .12 & - & -.19 & .21 & -.17 \\
\hline 6. Personal belief in a just world & .00 & .11 & .09 & -.13 & -.06 & - & $.41^{* *}$ & $.56^{* *}$ \\
\hline 7. Self - compassion & -.24 & -.03 & .09 & .23 & .06 & .29 & - & .26 \\
\hline 8. Body appreciation & -.26 & -.26 & .21 & $.34 *$ & .03 & $.32^{*}$ & $.68^{* *}$ & - \\
\hline
\end{tabular}

Note: For gender, $0=$ men, $1=$ women 


\section{Results}

Data analysis was done by using SPSS 20 (Statistical Package for Social Sciences. T test, Pearson Product Moment Correlation and moderation analysis through hierarchal regression analyses were performed.

Results of correlation analysis in table 3 suggest that personal belief in just world was positively related to body appreciation in both groups of individuals with amputation. Self - compassion was positively related to body appreciation in those individuals with amputation who used prosthesis. Among demographic variables only personal income was positively related to body appreciation in individual with amputation who used prosthesis. Therefore, in regression analysis only personal income was included as control variable.

Moderation through regression analysis with boot strap of 1000 was performed in order to see if personal belief in a just world and self - compassion predicted body appreciation similarly or differently in two groups. Findings of moderation analysis through hierarchal regression (Table 3 ) revealed that overall model explained $53 \%$ variance in body appreciation with $F(6,71)=13.65, p<.001$. With demographic variables i.e., personal income and group in Block 1, the model explained $20 \%$ of variance in body appreciation with $F(2,75)=9.54, p<.001$. Result revealed that group was the significant predictor of body appreciateion. Individuals with amputation using prosthesis had better body appreciation as compared to individuals with individuals with amputation not using prosthesis.

When personal belief in a just world and self compassion were added in Block 2, the model explained additional $26 \%$ of variance in body appreciation $\Delta F(2,73)=17.47, p<.001$. Personal belief in just world and self - compassion positively predicted body appreciation in individuals with amputation using prosthesis. Further individuals using prosthesis had better body appreciation than those who were not using prosthesis.

When the interactions of personal belief in a just world and self - compassion were added in Block 3, the model further explained $7 \%$ of variance in body appreciation $\Delta F(2,71)=5.72, \mathrm{p}=.005$, Results revealed that interaction of self - compassion with group was a positive predictor of body appreciation which shows that relationship between self - compassion and body appreciation differed in two groups.

To further explore the interaction effect, results were then analyzed by plotting the predicted values of body appreciation for each group (amputated individuals using prosthesis and amputated individuals not

Table 4: Moderation through Hierarchical Regression Predicting Body Appreciation from Personal Belief in Just World and Self - Compassion $(\mathrm{N}=78)$.

\begin{tabular}{|c|c|c|c|c|c|c|c|c|c|c|c|c|}
\hline \multirow[t]{2}{*}{ Predictor } & \multicolumn{2}{|c|}{ Step1 } & \multicolumn{2}{|c|}{$\begin{array}{l}\text { Bootstrap } \\
95 \% \text { CI }\end{array}$} & \multicolumn{2}{|c|}{ Step 2} & \multicolumn{2}{|c|}{$\begin{array}{l}\text { Bootstrap } \\
95 \% \text { CI }\end{array}$} & \multicolumn{2}{|c|}{ Step 3} & \multicolumn{2}{|c|}{$\begin{array}{c}\text { Bootstrap } \\
95 \% \text { CI }\end{array}$} \\
\hline & B & SE & LL & $\mathrm{UL}$ & B & SE & LL & $\mathrm{UL}$ & B & SE & LL & UL \\
\hline Constant & 23.91 & & & & 25.74 & & & & 25.89 & & & \\
\hline 1. Personal Income & .00 & .00 & .00 & -.00 & -.00 & .00 & -.00 & .00 & -.00 & .00 & -.00 & .00 \\
\hline 2. Group & $10.62 * *$ & 2.41 & 5.44 & 15.07 & $7.26 * *$ & 2.21 & 2.89 & 11.32 & $7.12 * *$ & 2.06 & 2.93 & 11.01 \\
\hline $\begin{array}{l}\text { 3. Personal Belief in } \\
\text { Just World }\end{array}$ & & & & & $.29 *$ & .12 & .06 & .54 & $.59 * *$ & .18 & .19 & .88 \\
\hline 4. Self - Compassion & & & & & $.59 * *$ & .17 & .25 & .92 & .05 & .27 & -.54 & .55 \\
\hline $\begin{array}{l}\text { 5. Personal Belief in } \\
\text { Just World X Groups }\end{array}$ & & & & & & & & & -.40 & .23 & -.83 & .04 \\
\hline $\begin{array}{l}\text { 6. Self - compassion } \mathrm{X} \\
\text { Groups }\end{array}$ & & & & & & & & & $.95^{* *}$ & .30 & .38 & 1.67 \\
\hline$R^{2}$ & $.20 * * *$ & & & & $.46 * * *$ & & & & $.53 * * *$ & & & \\
\hline$\Delta R^{2}$ & $.20 * * *$ & & & & $.26 * * *$ & & & & $.07 * *$ & & & \\
\hline
\end{tabular}

Note. Group (Individuals with amputation not using prosthesis $=0$, Individuals with amputation using prosthesis $=1$ ) $* \mathrm{p}<.05, * * \mathrm{p}<.01, * * * \mathrm{p}<.001$ 


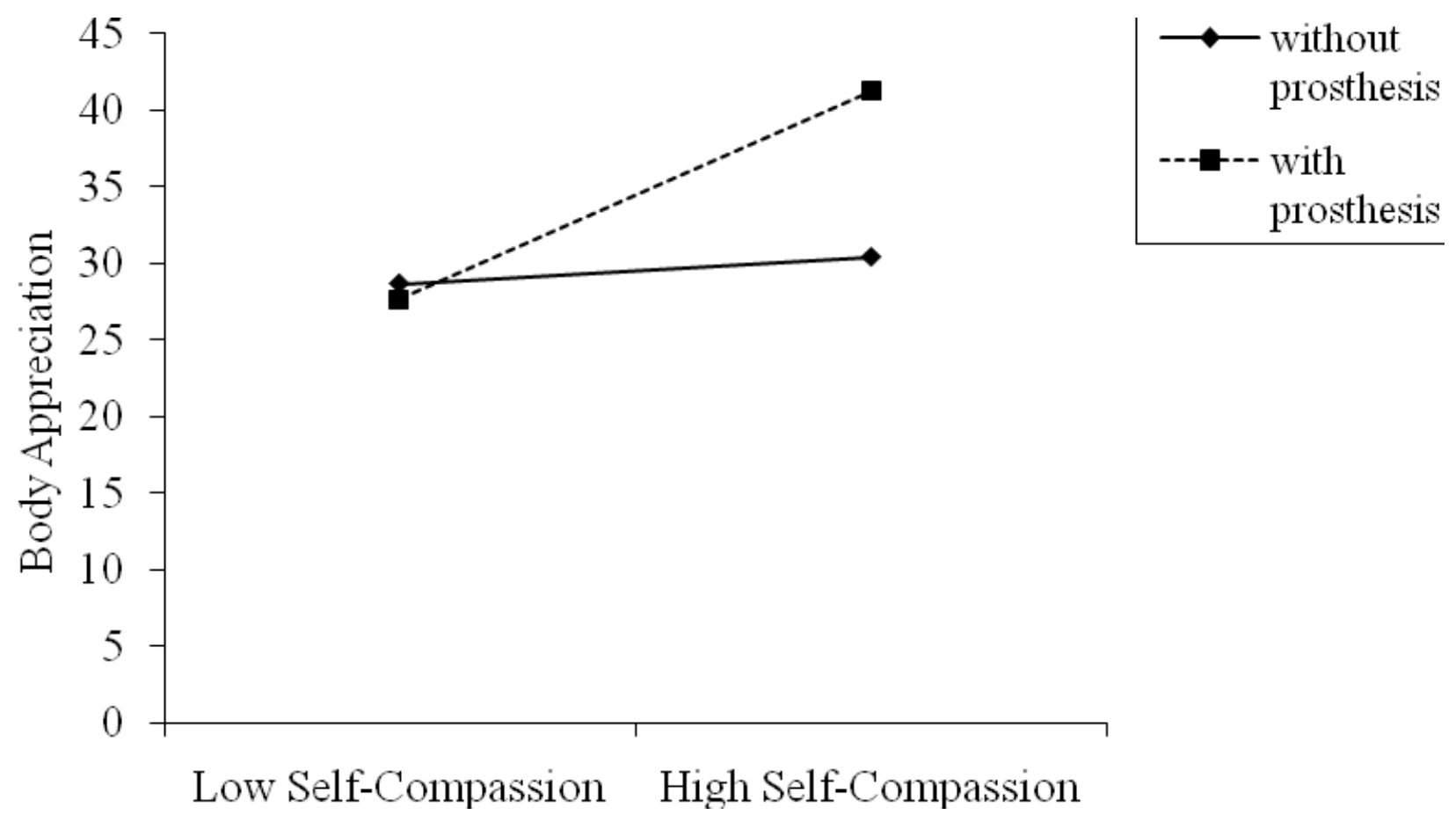

Fig. 1: The Interaction of groups and Self - Compassion for Body Appreciation.

using prosthesis) using simple slope analysis. ${ }^{19}$ The result revealed that self - compassion predicted body appreciation in amputated individuals using prosthesis. $(\mathrm{B}=0.94, p<.001)$ but did not predict body appreciation in individuals not using prosthesis $(\mathrm{B}=0.05$, $p=.84)$.

In a nutshell, personal belief in a just world positively predicted body appreciation in both groups, however, self - compassion positively predicted body appreciation among individuals who used prosthesis.

\section{Discussion}

Personal belief in just world helps individuals in improving body appreciation similarly in both groups. Findings of the current study also support the role of personal belief in just world as a personal resource and equally adaptive in both adverse ${ }^{6,7}$ and less - adverse situations. ${ }^{8,9}$ Personal belief in just world being the positive illusion help individuals to evaluate their life circumstances as to preserve their just world belief and provides sense of control in them. Further, Both individuals living in unfair and fair situations in order to restore their just world belief interpret their life events as less unfair and have more trust on being treated fairly and hence well - being is maintained and enhanced. Thus it is very likely that the belief that person has what he or she deserves helps the individuals to respect and appreciate their bodies whether they use prosthesis or not.

Self - compassion was found to be unexpectedly related to body appreciation in individuals with amputation using prosthesis but not in individuals not using prosthesis. This finding is in contradiction to the researches which conclude that in traumatic situations selfcompassion helps to combat with harsh situations. ${ }^{10-13}$ It might be that use of prosthesis helps people to be compassionate to themselves which in turn leads to appreciate their body. Further researches need to be done to clarify this relationship.

The current study added empirical evidence in the existing literature of personal belief in just world and self - compassion. Further added knowledge in the field of health psychology and Psych - prosthetics. Although present study had number of limitation i.e. sample was mainly comprised of male gender, traumatic and unilateral amputation. It is recommended that further studies should include various causes of amputation, age groups and study along with other psychological variables. 


\section{Conclusion}

Use of prosthesis helps in body appreciation of individuals with amputation. Over and above the use of prosthesis, personal belief in a just world is a personal resource that plays its role in maintaining body appreciation.

\section{References}

1. Gallagher P, Desmond D, Maclachlan M. Psychprosthetics. Springer Science, 2008.

2. Armstrong - James L. Body image and psychosocial adjustment following the amputation of a limb. Journal of Aesthetic Nursing, 2015; 4 (6).

3. Falvo DR. Medical and Psychosocial Aspects of Chronic Illness and Disability. Jones and Bartlett Learning, 2005.

4. Tylka TL. Positive psychology perspectives on body image. In T. F. Cash and L. Smolak (Eds.), Body image: A handbook of science, practice, and prevention (pp. 56-64). New York: Guilford. 2011.

5. Dalbert, C. The Justice motive as a personal resource: Dealing with challenges and critical life events. Plenum Press, 2001.

6. Dzuka J, Dalbert C. Mental health and personality of Slovak unemployed adolescents: The impact of belief in a just world. Journal of Applied Social Psychology, 2002; 32: 732-757.

7. Correia I, Kamble SV, Dalbert C. Belief in a just world and well - Being of bullies, victims and defenders: A study with Portuguese and Indian students. Anxiety, Stress and Coping, 2009; 22 (5): 497-508.

8. Fatima J, Suhail K. Belief in a just world and subjective well - being: mothers of normal and Down syndrome children. International Journal of Psychology, 2010; 45 (6): 461-468.
9. Kamble SV, Dalbert C. Belief in a just world and wellbeing in Indian Schools. International Journal of Psychology, 2012; 47 (4): 269-278.

10. Neff KD. Self - Compassion. William Morrow, 2011.

11. Przezdziecki A, Sherman KA, Baillie A, Taylor A, Foley E, Stalgis - Bilinski K. My changed body: breast cancer, body image, distress and self - compassion. Psycho - Oncology, 2012; 22 (8): 1872-1879.

12. Ferreira C, Pinto - Gouveia P, Ferreira C. Self - compassion in the face of shame and body image dissatisfaction: Implications for eating disorders. Eating Behaviors, 2013; 14 (2): 207-2010.

13. Wasylkiw L, Mackinnon AL, Maclellan AM. Exploring the link between self - compassion and body image in university women. Body Image, 2012; 9 (2): 236-245.

14. Fatima I, Khalid R. Some aspects of reliability and validity of beliefs in a just world Questionnaire. Pakistan Journal of Social and Clinical Psychology, 2007; 5: 1524.

15. Dalbert C. The world is more just for me than generally: About the Personal Belief in a Just World Scale's validity. Social Justice Research, 1999; 12: 79-98.

16. Shaukat J, Zafar N, Kausar R. Self - Compassion and positive psychological functioning in women with primary and secondary infertility. Unpublished masters dissertation, University of The Punjab, Lahore, Pakis$\tan , 2013$.

17. Raes F, Pommier E, Neff KD, Van Gucht D. Construction and factorial validation of a short form of the Self Compassion Scale. Clinical Psychology and Psychotherapy, 2011; 18: 250-255.

18. Avalos L, Tylka TL, Wood - Barcalow N. The body appreciation scale: development and psychometric evaluation. Body Image, 2006; 2 (3): 285-297.

19. Dawson JF. Moderation in management research: What, why, when and how. Journal of Business and Psychology, 2014; 29: 1-19. 